\title{
Esophageal Body Motility for Clinical Assessment in Patients with Refractory Gastroesophageal Reflux Symptoms
}

\author{
Liuqin Jiang, ${ }^{1 *}$ Bixing Ye, ${ }^{1}$ Ying Wang, ${ }^{2}$ Meifeng Wang, ${ }^{1}$ and Lin Lin ${ }^{1 *}$ \\ ${ }^{I}$ Department of Gastroenterology, The First Affiliated Hospital of Nanjing Medical University, Nanjing, Jiangsu, China; and ${ }^{2}$ Department of \\ Gastroenterology, Jiangsu Province Official Hospital, Nanjing; Jiangsu, China
}

\section{Background/Aims}

Little data exists about esophageal body dysmotility and reflux patterns in refractory gastroesophageal reflux disease (RGERD) patients off therapy. We aimed to evaluate effects of esophageal body dysmotility on reflux parameters in RGERD patients by combining impedance-pH monitoring and high-resolution manometry (HRM).

\section{Methods}

We retrospectively reviewed the impedance-pH data and HRM metrics in patients with refractory gastroesophageal reflux symptoms. Impedance-pH monitoring and manometric data were compared between 2 groups: ineffective esophageal motility (IEM) and normal motility.

\section{Results}

Forty-eight patients (30 males, mean age 54.5 years) were included (16 erosive esophagitis, 24 non-erosive reflux disease, and 8 functional heartburn), amongst which 24 subjects showed IEM, and others had normal motility. Number of patients who had a large break in the IEM group was significantly higher than that of normal motility patients. IEM group had more patients with weakly acid reflux and long term acid reflux than the normal group $(P=0.008, P=0.004$, respectively). There was no statistical difference in baseine impedance levels from $z 4$ to $z 6$ between the 2 groups $(2911 \pm 1160 \Omega$ vs $3604 \pm 1232 \Omega, 2766 \pm 1254 \Omega$ vs $3752 \pm 1439$ $\Omega, 2349 \pm 1131 \Omega$ vs $3038 \pm 1254 \Omega$, all $P>0.05$ ). Acid exposure time, numbers of long term acid reflux and weakly acid reflux showed strong negative correlation with esophageal body motility and/or lower esophageal sphincter function.

\section{Conclusions}

IEM was associated more with acid exposure, abnormal weakly acid reflux, and long term acid reflux in RGERD patients. These data suggested the role of esophageal body dysmotility in the pathophysiological mechanisms of RGERD patients.

\section{(J Neurogastroenterol Motil 2017;23:64-71)}

\section{Key Words}

Electric impedance; Esophageal dysmotility; Gastroesophageal reflux disease; Manometry

Received: March 14, 2016 Revised: June 18, 2016 Accepted: August 2, 2016

(.) This is an Open Access article distributed under the terms of the Creative Commons Attribution Non-Commercial License (http://creativecommons. org/licenses/by-nc/4.0) which permits unrestricted non-commercial use, distribution, and reproduction in any medium, provided the original work is properly cited.

${ }^{*}$ Correspondence: Liuqin Jiang and Lin Lin are equally responsible for this study. Liuqin Jiang, MD Department of Gastroenterology, The First Affiliated Hospital of Nanjing Medical University, Nanjing, Jiangsu 210029, China Tel: +86-13951017379, Fax: +86-25-83716920, E-mail: jiangliuqin@163.com Lin Lin, MD, PhD Department of Gastroenterology, The First Affiliated Hospital of Nanjing Medical University, Nanjing, Jiangsu 210029, China Tel: +86-13951709069, Fax: +86-25-83716920, E-mail: lin9100@aliyun.com 


\section{Introduction}

Gastroesophageal reflux disease (GERD) is defined as a condition in which the reflux of stomach contents causes troublesome symptoms such as regurgitation, heartburn, chest pain, and/ or complications. ${ }^{1}$ GERD is a common disease of digestive system, and an increasing prevalence of GERD has been observed in western countries and Asia. ${ }^{2,3}$ As we all know the first line of treatment for GERD is the proton pump inhibitor (PPI); ${ }^{4}$ however, up to $40 \%$ of patients failed to control their symptoms on a PPI therapy. Recent study showed that approximately one third of the patients with refractory reflux symptoms suffered from disorders other than reflux related disease, predominantly functional heartburn $(\mathrm{FH}){ }^{6}$ The pathological mechanism of refractory GERD (RGERD) is remains unclear, multiple factors have been proposed, including abnormal esophageal motility. ${ }^{5,7}$

Impaired esophageal motility is a common finding in GERD patients, including reduced lower esophageal sphincter (LES) basal pressure, extended transient LES relaxation, low peristaltic amplitude, and increased intra-abdominal pressure. ${ }^{8-13}$ While the role of LES in the pathogenesis of GERD has been studied extensively, less attention has been paid to esophageal body peristalsis, even though we believe esophageal peristalsis contribute to esophageal clearance. Previous studies have shown that abnormal esophageal clearance of refluxed content might be induced by impaired esophageal motility. ${ }^{8,9}$ Ineffective esophageal motility (IEM), which is characterized by $50 \%$ or more of failed or weak contractions, ${ }^{14}$ was proposed to have more clinical and functional relevance, and to be associated with abnormal bolus transit. ${ }^{15-17}$

High-resolution manometry (HRM) is a more user-friendly and accurate technology than conventional manometry. This technique allows for a dynamic representation of the pressure pattern throughout the entire esophagus. ${ }^{18-20}$ Twenty-four-hour multichannel intraluminal impedance-pH monitoring (MII-pH monitoring) is a sensitive method to detect and characterize reflux events including physiological and pathological acid reflux, weakly acid reflux, and alkaline reflux. ${ }^{21,22}$ The patients with refractory gastroesophageal reflux symptoms were classified into reflux related disease and non-reflux related disease by MII-pH monitoring. ${ }^{23,24}$ Baseline impedance level (BIL) is one of the parameters measured by MII$\mathrm{pH}$ monitoring, and it reflects the intrinsic electrical conductivity of the esophageal wall. Previous studies have revealed that lower BILs were observed in GERD patients compared with $\mathrm{FH}$ patients and healthy subjects, thus demonstrating BILs correlated with acid re- flux parameters. Therefore, BILs are considered as an indicator of esophageal mucosal integrity. ${ }^{25-28}$

There are, however, limited studies comparing the main manometric features, motility patterns, and reflux parameters in RGERD. Our study explored the use of MII-pH monitoring and HRM to investigate Chinese patients with refractory gastroesophageal reflux symptoms off PPI therapy. The primary aim of the present study was to compare abnormal reflux features and BILs composition in well defined subgroups of esophageal body dysmotility, sub-classified by means of HRM. A secondary aim was to assess the correction between $\mathrm{pH}$-impedance features and manometry metrics in the patients with refractory gastroesophageal reflux symptoms off therapy.

\section{Materials and Methods}

\section{Study Subjects}

This retrospective study was approved by the Ethical Committee of First Affiliated Hospital of Nanjing Medical University. All subjects were from the First Affiliated Hospital of Nanjing Medical University outpatient clinics from Jan 2014 to Feb 2016 in this study. Inclusion criteria included age of 18 years or older and any gender. All patients had typical heartburn or regurgitation, lasting $>6$ months, and their reflux disease questionnaire scores were not less than $12 .{ }^{29}$ All patients were treated with omeprazole $20 \mathrm{mg}$ or rabeprazole $10 \mathrm{mg}$ bid for at least 12 weeks, and their improvement of symptoms was $<50 \%$ who were defined as refractory. ${ }^{23}$ All subjects underwent endoscopy at 1 month before analysis, and the degree of mucosal injury was graded according to the Los Angeles classification. ${ }^{30}$ Patients were excluded if they had a history of peptic ulcer, gastrointestinal tumor or surgery, or severe esophageal motility disorders. In addition, subjects were also excluded if they were found to have abnormalities other than erosive esophagitis or chronic superficial gastritis. In addition, all identifying information about the patients was removed from our records before analyses in order to protect the patients' privacy.

\section{High-resolution Manometry}

Subjects off PPIs, $\mathrm{H}_{2}$-antagonist or prokinetic drug therapy at least 1 week underwent HRM and MII-pH monitoring. The HRM catheter (Given Imaging, Duluth, GA, USA) was placed transnasally in order to record the pressure from the hypopharynx to the stomach. The manometric protocol included 1-minute baseline recording and 10 swallows of $5 \mathrm{~mL}$ of warm water. The HRM 
results were analyzed using the Manoview analysis software (Given Imaging). According to the Chicago Classification Criteria version $3.0,{ }^{14}$ ineffective esophageal motility (IEM) was defined by $50 \%$ or more ineffective swallows, which had DCI $<450 \mathrm{mmHg} \cdot \mathrm{sec} \cdot \mathrm{cm}$. Based on the distance between the LES and crural diaphragm (CD), 3 subtypes of esophagogastric junction (EGJ) morphology were observed: type I (no discernible LES-CD separation), type II (1-2 cm LES-CD separation), and type III ( $>2 \mathrm{~cm}$ LES-CD separation). The following metrics were recorded: integrated relaxation pressure (IRP), LES basal pressure, LES length, proximal esophageal pressure (PEP), middle esophageal pressure (MEP), distal esophageal pressure, distal contractile integral (DCI), upper esophageal sphincter (UES) basal pressure, and large breaks.

\section{Esophageal Multichannel Intraluminal Impedance and $\mathrm{pH}$ Monitoring}

Subjects underwent MII-pH monitoring using an ambulatory monitoring system (Given Imaging). The catheter was placed in certain place of the distal esophagus through the nasal cavity. The $\mathrm{pH}$ sensor was placed at $5 \mathrm{~cm}$ above the LES (which was located by HRM), and 6 impedance values (z1, z2, z3, z4, z5, and z6) were recorded at 6 sites $(17,15,9,7,5$, and $3 \mathrm{~cm}$ above the LES, respectively). Patients were asked to record the onset of all heartburn or regurgitation symptoms, record meal times, and time of assuming the supine posture.

The following reflux parameters were recorded: the number and type of reflux episodes; ${ }^{31}$ DeMeester score; number of long term acid reflux ( $>5$ minutes); percent of time $\mathrm{pH}<4$ (supine); and acid exposure time (AET). AET was defined as the distal esophageal total time with $\mathrm{pH}$ below 4 , divided by the total time of monitoring. BILs were assessed in a manner blinded to the diagnostic results at 3 time points (around 00:00 am, 10:00 am, and 4:00 pm), avoiding proximity to any period of swallowing or reflux. Each BIL represents the average level of 3 suitable baseline levels around each time point. We chose BILs from the fifth impedance channel (z5, $5 \mathrm{~cm}$ above the LES) to analyze their correction with reflux parameters and HRM parameters, where there was a $\mathrm{pH}$ sensor to ensure that BILs were selected just when the $\mathrm{pH}$ was $>6$.

The data of reflux events and parameters were measured by automatic analysis software of the monitoring system with manual modifications by the 2 investigators (Liuqin Jiang and Bixing Ye). Reflux episodes were calculated by acid, weakly acid and alkaline according to a consensus report. ${ }^{32}$ Abnormal acid exposure was defined as the AET exceeding 4.2\%. The patients were classified as having abnormal reflux if reflux parameters such as reflux percent time and number of reflux episodes were above the normal limit. Symptom correlation with reflux was evaluated by symptom index (SI). SI was defined as the number of times the symptom occurred when reflux episodes took place, divided by the total number of times the symptom was reported, multiplied by 100 percent. $^{33}$ A SI $\geq 50 \%$ was considered as positive, which was calculated in terms of acid reflux related, weakly acid reflux related, and alkaline reflux related, respectively. ${ }^{34}$ The subjects with AET $<4.2 \%$, no abnormal reflux, and $\mathrm{SI}<50 \%$ were considered as $\mathrm{FH}^{35}$

\section{Statistical Methods}

Data are expressed as means $\pm \mathrm{SD}$. We used Student's $t$ test when 2 groups were compared, and the variance for difference in mean values was analyzed. Comparisons of proportions were calculated using the $x^{2}$ test. Correlation between HRM and $\mathrm{pH}$ impedance parameters were performed with Pearson's correlation coefficient (two-tailed). A $P<0.05$ was considered statistically significant. Statistical analysis was performed using SPSS version 19.0 for windows (SPSS, Chicago, IL, USA).

\section{Results}

\section{Demographic and Clinical Characteristics}

A total of 48 consecutive patients (30 males, mean age $54.5 \pm$ 15.2 years) with refractory gastroesophageal reflux symptoms were included for analysis. All patients tolerated MII-pH monitoring and HRM, and had no adverse reaction. Sixteen erosive esophagitis patients (3 with Los Angeles classification grade C) and 32 non-erosive patients were confirmed under endoscopy, and none of patients were found to have Barrett's esophagus. Base on the results of MII-pH monitoring, 20 patients had abnormal acid reflux, 12 had abnormal weakly acid reflux, and 28 had abnormal alkaline reflux, while 8 subjects were diagnosed as $\mathrm{FH}$; while there were 14 patients with abnormal acid reflux SI (+), 10 with abnormal weakly acid reflux SI $(+)$, and 8 with abnormal alkaline reflux SI $(+)$. Detailed demographic data and MII-pH monitoring parameters are summarized in Table 1.

\section{Manometry Profile, pH-impedance Parameters and Baseline Impedance Levels}

All subjects were eligible for HRM testing, and none of subjects were found to have the evidence of achalasia, EGJ outflow obstruction, and major peristalsis disorders. Twenty-four subjects evaluated by HRM showed IEM, and the other 24 had normal 
esophageal motility. Thirty-six (7.5\%) large breaks of esophageal peristalsis were observed among 480 wet swallows.

The IEM group had significantly more large break occurrences than the normal motility group $(P<0.001)$. LES abdominal length, PEP, MEP, distal esophageal pressure, and DCI were significantly lower in the IEM group than the normal group $(P$

Table 1. Baseline Characteristics of Subjects

\begin{tabular}{lc}
\multicolumn{1}{c}{ Characteristics } & $\begin{array}{c}\text { Total patients } \\
(\mathrm{n}=48)\end{array}$ \\
\hline Age (mean $\pm \mathrm{SD}, \mathrm{yr})$ & $54.5 \pm 15.2$ \\
Male (n [\%]) & $30(62.5)$ \\
Upper endoscopy finding (n [\%]) & $16(33.3)$ \\
Erosive esophagitis & $24(50.0)$ \\
Non-erosive reflux disease & $8(16.7)$ \\
FH (n [\%]) & $20(41.7)$ \\
Patients with abnormal reflux (n [\%]) & $12(25.0)$ \\
Acid reflux & $28(58.3)$ \\
Weakly acid reflux & \\
Alkaline reflux & 14 \\
Symptom reflux association $(\mathrm{n})$ & 10 \\
Acid reflux SI $(+)$ & 8 \\
Weakly acid reflux SI $(+)$ & \\
Alkaline reflux SI $(+)$ &
\end{tabular}

$\mathrm{FH}$, functional heartburn; SI, symptom index.
$=0.014, P<0.001, P=0.003, P<0.001$, respectively). UES and LES basal pressure, IRP, numbers of large breaks, numbers of different type EGJ morphology were similar between the 2 groups (Table 2).

The IEM group had more patients with abnormal weakly acid reflux and with long term acid reflux than the normal group $(P=$ 0.008 and $P=0.004$, respectively), however, other MII-pH monitoring parameters were similar between the 2 groups (Table 3 ).

BILs from $z 4$ to $z 6$ were a little lower in IEM group than normal group, but there was no statistically significant difference (2911 $\pm 1160 \Omega$ vs $3604 \pm 1232 \Omega, P=0.172 ; 2766 \pm 1254 \Omega$ vs $3752 \pm 1439 \Omega, P=0.087 ; 2349 \pm 1131 \Omega$ vs $3038 \pm 1254 \Omega$, $P=0.171)$ (Figure).

\section{Correlation Between pH-impedance Parameters and High-resolution Manometry Metrics}

There were significant relationships between HRM metrics and MII-pH monitoring parameters (Table 4). AET showed significant negative correlation with PEP, MEP, and DCI ( $r=-0.479,-0.451,-0.463$, respectively, all $P<0.05$ ). Similarly, numbers of long term acid reflux had significant negative correlation with PEP, MEP, DCI, and LES length $(r=-0.502,-0.455$, $-0.475,-0.579$, respectively, all $P<0.05)$. Numbers of weakly acid reflux showed negative correlation with DCI, LES basal pressure, and $\operatorname{IRP}(r=-0.438,-0.452,-0.612$, respectively, all $P<0.05)$.

Table 2. High-resolution Manometry Metrics of Ineffective Esophageal Motility and Normal Motility

\begin{tabular}{|c|c|c|c|}
\hline & $\operatorname{IEM}(\mathrm{n}=24)$ & Normal $(n=24)$ & $P$-value \\
\hline Age (mean $\pm \mathrm{SD}, \mathrm{yr})$ & $54.7 \pm 14.4$ & $54.4 \pm 16.6$ & 0.970 \\
\hline Male (n [\%]) & $18(75.0)$ & $12(50.0)$ & 0.074 \\
\hline $\mathrm{UESP}($ mean $\pm \mathrm{SD}, \mathrm{mmHg})$ & $61.0 \pm 26.3$ & $97.5 \pm 52.5$ & 0.075 \\
\hline $\mathrm{LESP}($ mean $\pm \mathrm{SD}, \mathrm{mmHg})$ & $16.0 \pm 10.6$ & $22.0 \pm 8.0$ & 0.129 \\
\hline $\mathrm{LESL}($ mean $\pm \mathrm{SD}, \mathrm{mmHg})$ & $3.3 \pm 1.2$ & $4.1 \pm 0.9$ & 0.102 \\
\hline LES abdominal length (mean $\pm \mathrm{SD}, \mathrm{cm})$ & $1.9 \pm 0.6$ & $2.5 \pm 0.9$ & 0.033 \\
\hline $\mathrm{IRP}($ mean $\pm \mathrm{SD}, \mathrm{mmHg})$ & $8.1 \pm 7.4$ & $10.6 \pm 4.2$ & 0.320 \\
\hline Large breaks (n [\%]) & $30(12.5)$ & $6(2.5)$ & $<0.001$ \\
\hline $\mathrm{PEP}($ mean $\pm \mathrm{SD}, \mathrm{mmHg})$ & $42.7 \pm 14.3$ & $71.2 \pm 26.6$ & 0.014 \\
\hline $\operatorname{MEP}($ mean $\pm \mathrm{SD}, \mathrm{mmHg})$ & $47.3 \pm 11.7$ & $91.3 \pm 26.6$ & $<0.001$ \\
\hline $\mathrm{DEP}($ mean $\pm \mathrm{SD}, \mathrm{mmHg})$ & $46.9 \pm 18.8$ & $88.8 \pm 36.0$ & 0.003 \\
\hline $\mathrm{DCI}($ mean $\pm \mathrm{SD}, \mathrm{mmHg} \cdot \mathrm{sec} \cdot \mathrm{cm})$ & $349.8 \pm 204.1$ & $1403.3 \pm 720.3$ & $<0.001$ \\
\hline \multicolumn{4}{|l|}{ EGJ morphology (n [\%]) } \\
\hline Type I & $16(66.7)$ & $20(83.3)$ & 0.182 \\
\hline Type II & $6(25.0)$ & $3(12.5)$ & 0.267 \\
\hline Type III & $2(8.3)$ & $1(4.2)$ & 0.551 \\
\hline
\end{tabular}

IEM, ineffective esophageal motility; UESP, upper esophageal sphincter basal pressure; LESP, lower esophageal sphincter basal pressure; IRP, integrated relaxation pressure; PEP, proximal esophageal pressure; MEP, middle esophageal pressure; DEP, distal esophageal pressure; DCI, distal contractile integral; EGJ, esophagogastric junction. 
Table 3. Endoscopy Findings and Multichannel Intraluminal Impedance-pH Monitoring Parameters of Ineffective Esophageal Motility and Normal Motility

\begin{tabular}{lccc}
\hline & IEM & Normal & $P$-value \\
\hline Upper endoscopy finding (n [\%]) & & & \\
Erosive esophagitis & $8(33.3)$ & $1(33.3)$ & 0.551 \\
LA-C & $2(8.3)$ & $4(16.7)$ & 0.900 \\
FH (n [\%]) & $4(16.7)$ & $4.2 \pm 4.6$ & \\
AET (mean \pm SD, \%) & $4.4 \pm 3.3$ & $86.2 \pm 28.6$ & 0.517 \\
Reflux episodes (mean $\pm \mathrm{SD}, \mathrm{n})$ & & $17.6 \pm 5.7$ & 0.220 \\
Acid reflux & $64.5 \pm 16.4$ & $3.3 \pm 1.8$ & 0.743 \\
Weakly acid reflux & $31.6 \pm 9.5$ & $8(33.3)$ & 0.242 \\
Alkaline reflux & $4.1 \pm 1.8$ & $2(8.33)$ & 0.008 \\
Patients with abnormal reflux (n [\%]) & $12(50.0)$ & $16(66.7)$ & 0.242 \\
Acid reflux & $10(41.7)$ & $8(33.3)$ & 0.004 \\
Weakly acid reflux & $12(50.0)$ & $18(75.0)$ & \\
Alkaline reflux & & \\
Long term acid reflux & & \\
\hline
\end{tabular}

IEM, ineffective esophageal motility; LA-C, Los Angeles classification grade C; FH, functional heartburn; AET, acid exposure time.

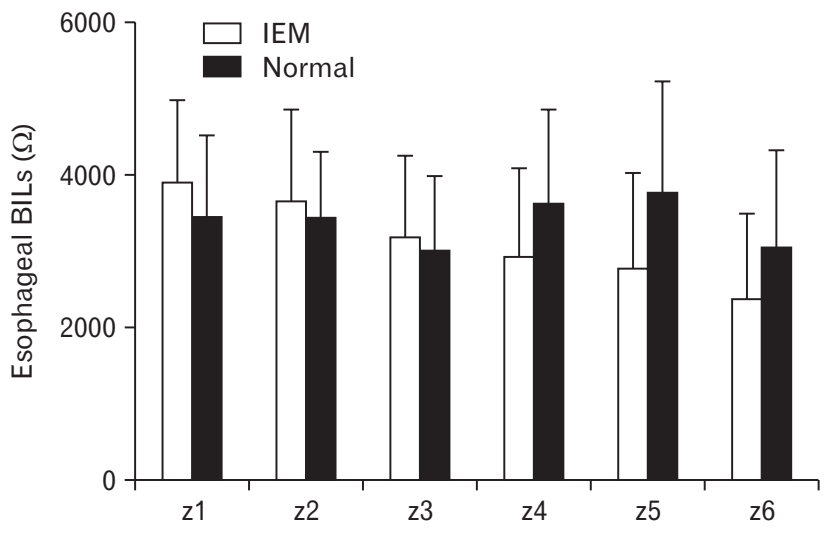

Impedance values from different esophageal sites

Figure. Baseline impedance levels (BILs) from each channel in ineffective esophageal motility (IEM) and normal motility groups. BILs from $\mathrm{z} 4$ to $\mathrm{z} 6$ were a little lower in the IEM group than the normal group, but there was no statistical difference (all $P>0.05$ ).

Distal BIL showed significant correlation with UES basal pressure and $\operatorname{PEP}(r=0.489, P<0.05 ; r=0.634, P<0.05)$. However, there were no significant correlation between SI and HRM metrics.

\section{Discussion}

The role of IEM has not been well characterized in patients with RGERD. Ho et $\mathrm{al}^{36}$ demonstrated that half of GERD patients had been diagnosed with IEM on manometry, and patients with Barrett's esophagus had a strong predilection toward this abnormality. Our results were consistent with the above research: among all patients, no patients were observed with severe and major disorders of esophageal motility, but half of patients had IEM, and $7.5 \%$ of wet swallows were considered as large breaks of esophageal peristalsis.

We believe that in general, the more abnormal the esophageal peristalsis, the worse the gastroesophageal reflux. Diener et $\mathrm{al}^{15}$ reported that GERD patients with IEM were associated with longer esophageal acid exposure, more frequent and longer reflux episodes, and slower esophageal acid clearance than those without IEM. Our study demonstrated that there were more patients with weakly acid reflux and long term acid reflux in RGERD patients with IEM than those without IEM. But episodes of acid reflux or nonacid reflux were similar between the 2 groups. Our findings showed there were significant relationships between some of the HRM metrics and MII-pH monitoring parameters. AET, numbers of long term acid reflux, and numbers of weakly acid reflux were found to be significantly and negatively correlated with esophageal body motility; moreover, numbers of long term acid reflux and numbers of weakly acid reflux were also negatively correlated with LES function or length. However, there was no statistically significant correction between numbers of acid or non-acid reflux and esophageal body dysmotility in our data, and similarly between SI and esophageal dysmotility.

We have yet to figure out a clear explanation for our above findings. IEM was indicated to be more likely to be associated with 
Table 4. Correlation Between pH-impedance Parameters and High-resolution Manometry Metrics

\begin{tabular}{lcccccccc}
\hline & AET & $\begin{array}{c}\text { No. of long term } \\
\text { acid reflux }\end{array}$ & $\begin{array}{c}\text { Recumbent } \\
\text { acid reflux }\end{array}$ & $\begin{array}{c}\text { Acid reflux } \\
\text { episodes }\end{array}$ & $\begin{array}{c}\text { Weakly acid } \\
\text { reflux episodes }\end{array}$ & $\begin{array}{c}\text { Alkaline reflux } \\
\text { episodes }\end{array}$ & SI & Distal BIL \\
\hline UESP & 0.226 & 0.123 & 0.374 & 0.243 & 0.207 & 0.197 & -0.472 \\
PEP & $-0.479^{\mathrm{a}}$ & $-0.502^{\mathrm{a}}$ & -0.393 & -0.219 & -0.285 & -0.188 & 0.280 & $0.489^{\mathrm{a}}$ \\
MEP & $-0.451^{\mathrm{a}}$ & $-0.455^{\mathrm{a}}$ & -0.370 & -0.243 & -0.422 & -0.053 & 0.024 & 0.361 \\
DEP & -0.366 & -0.404 & -0.263 & -0.165 & -0.389 & -0.014 & 0.319 & 0.140 \\
DCI & $-0.463^{\mathrm{a}}$ & $-0.475^{\mathrm{a}}$ & -0.397 & -0.255 & $-0.438^{\mathrm{a}}$ & -0.123 & 0.206 & 0.360 \\
LESL & -0.371 & $-0.579^{\mathrm{b}}$ & -0.240 & -0.087 & -0.13 & 0.198 & 0.544 & 0.395 \\
LESP & -0.215 & -0.207 & -0.240 & -0.123 & $-0.452^{\mathrm{a}}$ & -0.158 & 0.291 & $0.417^{\mathrm{a}}$ \\
IRP & -0.158 & -0.342 & -0.282 & 0.033 & $-0.612^{\mathrm{b}}$ & -0.080 & 0.28 & 0.295 \\
\hline
\end{tabular}

AET, acid exposure time; SI, symptom index; BIL, Baseline impedance level; UESP, upper esophageal sphincter basal pressure; PEP, proximal esophageal pressure; MEP, middle esophageal pressure; DEP, distal esophageal pressure; DCI, distal contractile integral; LESL, lower esophageal sphincter length; LESP, lower esophageal sphincter basal pressure; IRP, integrated relaxation pressure.

Pearson's correlation coefficient, $r$. P-values were calculated using Pearson's correlation analysis.

${ }^{\mathrm{a}} P<0.05$ and ${ }^{\mathrm{b}} P<0.01$ were considered statistically significant.

impaired bolus transit and esophageal clearance, ${ }^{16,37}$ which could partly explain the above results. But how reflux occurs is a complex process, which is an imbalance between the ability of anti-reflux and reflux, and RGERD is more complicated than normal GERD. Previous studies had revealed that RGERD was more strongly related with weakly acid reflux and alkaline reflux than acid reflux. ${ }^{6,2438,39}$ Furthermore, long term usage of PPI might reduce the detective acid reflux episodes difference between the 2 groups. In addition, only 48 patients were enrolled in our study, and the small sample size might be related with the results. Overall, our data supported that esophageal motility might partly impact RGERD patients via esophageal body motility, including wave amplitude and DCI and LES function, but not only LES function.

Diener et $\mathrm{al}^{15}$ revealed that among patients with esophageal dysmotility, severe esophagitis was present more often. Other researchers also found that worse esophageal peristalsis was accompanied by more severe esophageal mucosal injury. ${ }^{8,40}$ In our study, no patients with Barrett's esophagus was observed, and the severity of esophagitis were similar between the 2 groups. While distal esophageal BILs were a little lower in patients with IEM than those without IEM, there was no statistical significance. Based on that BIL reflected the esophageal mucosal integrity, our data did not show significant difference in esophageal mucosal injury between the IEM and normal motility groups.

Overall, it is reasonable to hypothesize that the frequency of IEM increases in parallel with the severity of GERD. However, the severity of esophageal mucosal damage is the result of balancing between reflux materials and esophageal anti-reflux, and increased gastroesophageal reflux could lead to a reduction in esophageal compliance and an increased resistance during bolus movement with a consequent delayed bolus transport. IEM could be partly related to esophageal mucosal injury based on that IEM was associated with impaired bolus transit and esophageal clearance; $;^{16,37}$ moreover, it could be more complicated in RGERD patients. Long term usage of PPIs is unlikely to improve the RGERD patients' symptoms, but it could reduce esophageal inflammation and lead to negative endoscopy findings. In general, our results suggested that esophageal dysmotility alone could not explain the data above and that other mechanisms might be involved in esophageal mucosal injuries. But our findings about acid reflux episodes and esophageal mucosal injury between the 2 groups were parallel on the basis that esophageal mucosal injury relates more with acid reflux. ${ }^{41}$

According to our results, we believe that a more in-depth pathophysiological evaluation of IEM and reflux parameters could be of help to better investigate patients with refractory gastroesophageal reflux symptoms. Nevertheless, limitations exist in our study: (1) our study was retrospective, and we could not collect enough information such as smoking, drinking, BMI, detailed drugs except PPI, and the severity of reflux symptoms; (2) all patients came from our single clinical center, the numbers were limited, and we lack regular GERD patients and a normal population; and (3) there was high prevalence of esophagitis in our study, which might be associated with the design of the retrospective study and small sample size.

IEM still remains an under-recognized and under-treated condition. Only a limited handful of studies have presented the role of IEM in RGERD patients, and we still have no idea about whether the presence of IEM was a primary or secondary abnormality during the disease process. It is a challenge to administer effective treatments for persistent RGERD patients, on which more studies 
are required to clarify effective therapy to restore normal esophageal peristalsis and to improve reflux symptoms in RGERD patients with IEM.

In conclusion, this study evaluated up and coming variables of HRM and MII-pH monitoring in RGERD to assess the differences and similarities in RGERD patients with/without IEM. Based on our data, IEM was associated more with acid exposure, abnormal weakly acid reflux and long term acid reflux. We believe that the assessment of the relationship between esophageal motility and reflux parameters could help to further understand the pathophysiological mechanisms of RGERD. However, the results from our study warrant further research in RGERD patients to validate the effect of esophageal dysmotility, including the disorders of esophageal body peristalsis and LES.

\section{Financial support: None.}

\section{Conflicts of interest: None.}

Author contributions: Linqin Jiang, Bixing Ye, and Lin Lin conceived and designed the experiments; Linquin Jiang, Ying Wang, and Meifeng Wang performed the experiments; Linqin Jiang and Bixing Ye analyzed the data; Linqin Jiang, Bixing Ye, and Lin Lin contributed reagents/materials/analysis tools; and Linqin Jiang and Lin Lin wrote the manuscript.

\section{References}

1. Vakil N, van Zanten SV, Kahrilas P, Dent J, Jones R; Global Consensus Group. The Montreal definition and classification of gastroesophageal reflux disease: a global evidence-based consensus. Am J Gastroenterol 2006;101:1900-1920.

2. Moayyedi P, Talley NJ. Gastro-oesophageal reflux disease. Lancet 2006;367:2086-2100.

3. Wong BC, Kinoshita Y. Systematic review on epidemiology of gastroesophageal reflux disease in Asia. Clin Gastroenterol Hepatol 2006;4:398-407.

4. Fujiwara Y, Takahashi S, Arakawa T, et al. A 2008 questionnaire-based survey of gastroesophageal reflux disease and related diseases by physicians in East Asian countries. Digestion 2009;80:119-128.

5. Fass R, Sifrim D. Management of heartburn not responding to proton pump inhibitors. Gut 2009;58:295-309.

6. Herregods TV, Troelstra M, Weijenborg PW, Bredenoord AJ, Smout AJ. Patients with refractory reflux symptoms often do not have GERD. Neurogastroenterol Motil 2015;27:1267-1273.

7. Kahrilas PJ, Keefer L, Pandolfino JE. Patients with refractory reflux symptoms: what do they have and how should they be managed? Neurogastroenterol Motil 2015;27:1195-1201.
8. Kahrilas PJ, Dodds WJ, Hogan WJ, Kern M, Arndorfer RC, Reece A. Esophageal peristaltic dysfunction in peptic esophagitis. Gastroenterology 1986;91:897-904.

9. Kahrilas PJ, Dodds WJ, Hogan WJ. Effect of peristaltic dysfunction on esophageal volume clearance. Gastroenterology 1988;94:73-80.

10. Ang D, Blondeau K, Sifrim D, Tack J. The spectrum of motor function abnormalities in gastroesophageal reflux disease and Barrett's esophagus. Digestion 2009;79:158-168.

11. Kahrilas PJ. GERD pathogenesis, pathophysiology, and clinical manifestations. Cleve Clin J Med 2003;70(suppl 5):S4-S19.

12. Cho YK, Choi MG, Lim CH, et al. Impaired esophageal bolus transit in patients with gastroesophageal reflux disease and abnormal esophageal Acid exposure. Gut Liver 2012;6:440-445.

13. Ozin Y, Dagli U, Kuran S, Sahin B. Manometric findings in patients with isolated distal gastroesophageal reflux. World J Gastroenterol 2009; 15:5461-5464

14. Kahrilas PJ, Bredenoord AJ, Fox M, et al. The Chicago classification of esophageal motility disorders, v3.0. Neurogastroenterol Motil 2015;27:160-174.

15. Diener U, Patti MG, Molena D, Fisichella PM, Way LW. Esophageal dysmotility and gastroesophageal reflux disease. J Gastrointest Surg 2001;5:260-265.

16. Blonski W, Vela M, Safder A, Hila A, Castell DO. Revised criterion for diagnosis of ineffective esophageal motility is associated with more frequent dysphagia and greater bolus transit abnormalities. Am J Gastroenterol 2008;103:699-704.

17. Tutuian R, Castell DO. Clarification of the esophageal function defect in patients with manometric ineffective esophageal motility: studies using combined impedance-manometry. Clin Gastroenterol Hepatol 2004;2:230-236.

18. Ciriza-de-Los-Ríos C, Canga-Rodríguez-Valcárcel F. High-resolution manometry and impedance-pH/manometry: novel techniques for the advancement of knowledge on esophageal function and their clinical role. Rev Esp Enferm Dig 2009;101:861-869.

19. Pandolfino JE, Fox MR, Bredenoord AJ, Kahrilas PJ. High-resolution manometry in clinical practice: utilizing pressure topography to classify oesophageal motility abnormalities. Neurogastroenterol Motil 2009;21:796-806.

20. Pandolfino JE. High-resolution manometry: is it better for detecting esophageal disease? Gastroenterol Hepatol (N Y) 2010;6:632-634.

21. Shay S, Tutuian R, Sifrim D, et al. Twenty-four hour ambulatory simultaneous impedance and $\mathrm{pH}$ monitoring: a multicenter report of normal values from 60 healthy volunteers. Am J Gastroenterol 2004;99:10371043.

22. Bredenoord AJ, Tutuian R, Smout AJ, Castell DO. Technology review: esophageal impedance monitoring. Am J Gastroenterol 2007;102:187194.

23. Sifrim D, Zerbib F. Diagnosis and management of patients with reflux symptoms refractory to proton pump inhibitors. Gut 2012;61:13401354.

24. Kohata Y, Fujiwara Y, Machida H, et al. Pathogenesis of proton-pump inhibitor-refractory non-erosive reflux disease according to multichan- 
nel intraluminal impedance-pH monitoring. J Gastroenterol Hepatol 2012;27(suppl 3):58-62.

25. Farr Farré R, Blondeau K, Clement D, et al. Evaluation of oesophageal mucosa integrity by the intraluminal impedance technique. Gut 2011;60:885-892.

26. Kessing BF, Bredenoord AJ, Weijenborg PW, Hemmink GJ, Loots $\mathrm{CM}$, Smout AJ. Esophageal acid exposure decreases intraluminal baseline impedance levels. Am J Gastroenterol 2011;106:2093-2097.

27. Zhong C, Duan L, Wang K, et al. Esophageal intraluminal baseline impedance is associated with severity of acid reflux and epithelial structural abnormalities in patients with gastroesophageal reflux disease. J Gastroenterol 2013;48:601-610.

28. de Bortoli N, Martinucci I, Savarino E, et al. Association between baseline impedance values and response proton pump inhibitors in patients with heartburn. Clin Gastroenterol Hepatol 2015;13:1082-1088, e1.

29. Shaw MJ, Talley NJ, Beebe TJ, et al. Initial validation of a diagnostic questionnaire for gastroesophageal reflux disease. Am J Gastroenterol 2001;96:52-57.

30. Armstrong D, Bennett JR, Blum AL, et al. The endoscopic assessment of esophagitis: a progress report on observer agreement. Gastroenterology 1996;111:85-92.

31. Cho YK. How to interpret esophageal impedance $\mathrm{pH}$ monitoring. J Neurogastroenterol Motil 2010;16:327-330.

32. Sifrim D, Castell D, Dent J, Kahrilas PJ. Gastro-oesophageal reflux monitoring: review and consensus report on detection and definitions of acid, non-acid, and gas reflux. Gut 2004;53:1024-1031.

33. Singh S, Richter JE, Bradley LA, Haile JM. The symptom index. Differential usefulness in suspected acid-related complaints of heartburn and chest pain. Dig Dis Sci 1993;38:1402-1408.

34. Sifrim D, Holloway R, Silny J, et al. Acid, nonacid, and gas reflux in patients with gastroesophageal reflux disease during ambulatory 24-hour pH-impedance recordings. Gastroenterology 2001;120:1588-1598.

35. Surdea Blaga T, Dumitrascu D, Galmiche JP, Bruley des Varannes S. Functional heartburn: clinical characteristics and outcome. Eur J Gastroenterol Hepatol 2013;25:282-290.

36. Ho SC, Chang CS, Wu CY, Chen GH. Ineffective esophageal motility is a primary motility disorder in gastroesophageal reflux disease. Dig Dis Sci 2002;47:652-656.

37. Leite LP, Johnston BT, Barrett J, Castell JA, Castell DO. Ineffective esophageal motility (IEM): the primary finding in patients with nonspecific esophageal motility disorder. Dig Dis Sci 1997;42:1859-1865.

38. Takeshima F, Hashiguchi K, Onitsuka Y, et al. Clinical characteristics of patients with gastroesophageal reflux disease refractory to proton pump inhibitors and the effects of switching to $20 \mathrm{mg}$ esomeprazole on reflux symptoms and quality of life. Med Sci Monit 2015;21:4111-4121.

39. Yamashita H, Ashida K, Fukuchi T, et al. Combined pH-impedance monitoring and high-resolution manometry of Japanese patients treated with proton-pump inhibitors for persistent symptoms of non-erosive reflux disease. J Smooth Muscle Res 2012;48:125-135.

40. Savarino E, Gemignani L, Pohl D, et al. Oesophageal motility and bolus transit abnormalities increase in parallel with the severity of gastrooesophageal reflux disease. Aliment Pharmacol Ther 2011;34:476-486.

41. Sung HJ, Cho YK, Moon SJ, et al. Role of Acid and weakly acidic reflux in gastroesophageal reflux disease off proton pump inhibitor therapy. J Neurogastroenterol Motil 2012;18:291-297. 